at a fair decision upon the questions raised. It is impossible for persons who are deeply interested in these questions, and in the results of the investigation, to divest themselves of all feeling and bias, and to judge their own ideas and work from an absolutely impartial standpoint. It would probably happen in any inquiry, that if one of the parties implicated were allowed to Araw up the judgment, the result would not be unfavourable to itself. Most people appear satisfied, however, that this course should be taken when the question involved is that of the efficiency of the battleships uprn $u$ hich the defence of the British Empire would mainly depend in the event of war.

\section{FRANCIS ELGAR.}

\section{THE NEW LABORATORIES OF THE INSTITUTE OF CHEMISTRY.}

$\mathrm{A} \mathrm{T}$ length the members of the Institute of Chemistry may feel entitled to cry with Proteus, "Time is the nurse and breeder of all good," for now the object, kept steadily in view through evil report and good, though there was mighty little of the latter, has been achieved, and the Institute of Chemistry finds itself in the possession of a house with offices, council chamber, examination rooms, laboratories for examination, and everything handsome about it.

The successive councils are to be congratulated on the firmness with which they have resisted the numerous and persistent attempts which have been made by a somewhat important body of members to force the Institute into becoming a publishing and paper-producing body, thus adding another to the already too numerous chemical journals.

The Institute was not founded for this purpose; but the fact was forgotten again and again by those who were apparently unable to resist the temptation to spend the gradually accumulating funds of the Institute on "doing something," no matter what, but preferably holding meetings and printing a journal. The councils, however, proved wiser than some of their constituents, and held to the true view of their function, namely, that they were an examining and qualifying body.

Upwards of twenty years ago the passage of the Food and Drugs Act led to a series of appointments of public analysis that taken in the mass were little short of scandalous. The chemical profession had no corporate existence ; it had never been consulted in the matter of drafting the Act, and the Government of the day, though having eminent chemists at command, never asked any advice. County and borough, corporation and vestry, were required to appoint " analytical chemists," and, left to their own sweet will in making the selection, with results that can be more easily imagined than described. It was this that literally forced the then small number of men who were practising chemistry professionally, to organise themselves with a view, not of undoing the mischief already done, for that was irreparable, but of gradually supplying a body of men whose qualifications were vouched for by a searching examination.

These examinations, at first held in town and at a number of provincial centres, have gradually concentrated in London, and the increasing number of examinees at length warned the council that the time had come when the Institute must be able to examine under its own roof.

The presidency of Dr. Tilden has been signalised by the carrying through of this project. After a prolonged search, suitable premises were found at No. 30 Bloomsbury Square, and the lease purchased. The House Committee, consisting of the President and Treasurer, with
Prof. J. M. Thomson and Mr. R. J. Friswell, immediately set about planning the laboratory, the architectural work being placed in the hands of Mr. H. V. Lanchester.

The immediately surrounding property being residential, it was of great importance to prevent any nuisance from the escape of fumes, and the committee, in view of the almost universal failure of most of the fume apparatus in existing laboratories, placed themselves in the hands of one of their members whose experience as a chemical manufacturer led him to adopt the novel expedient of treating the laboratory as an acid factory, and scrubbing and burning the fumes, the latter by means of a specially constructed furnace, which also causes the draught by which the fumes are removed. So far this arrangement appears to work well, and it will no doubt be watched with interest by future builders of laboratories.

When the premises were taken over they consisted of a house of 36 feet frontage and 45 feet depth. Behind this lay a space of 60 feet by 36 feet, partly covered by an old building, once no doubt a stable, and partly occupied by an area and a built-out basement kitchen, which had a very large chimney, built independently of the house chimneys, and about 95 feet high and 18 inches square. The old building being removed, there remained an area of 34 by 36 feet for the principal laboratory, while the basement kitchen could be easily converted into a combustion laboratory, and its tall chimney--a factory shaft on a small scale-utilised for ventilating the fume cupboards and working benches.

The house faces nearly due west, and this permitted the laboratory to be lighted entirely from the north. As it was not possible to erect a lofty roof, it was decided to divide it into three gables, each having one side of glass, the other, turned towards the south, slated and matchboarded inside. These unglazed sides rise at an angle of $40^{\circ}$, and are so prolonged that the glazed sides, rising at an angle of $60^{\circ}$, meet them at an angle of $80^{\circ}$, and the entrance of direct sunlight is this prevented, and, except for a very short time in the middle of the day, at midsummer. The main laboratory, $35 \times 32$ feet, is fitted with thirty-two working benches, and a desk for the examiner; two fume chambers and one bench of muffles being arranged at each end. It is lined throughout with white glazed bricks, the floor is of 2 -inch pitchpine, and the working benches are of the same wood with mahogany edges, and tops saturated with high melting paraffin wax. Each bench has the necessary reagent shelves, seven drawers, and ample space with shelves beneath for the storage of large apparatus. It is also provided with two gas-cocks, a low-pressure water-cock, another for the supply of a condenser, and one high-pressure cock for a Sprengel filter pump. The sinks are circular, of saltglazed stoneware, and so arranged that each supplies accommodation for four benches. Under each bench, below the floor level, runs an 8-inch Doulton pipe (which gives off 3 -inch branches to each bench), and connects with a $\mathrm{I} 2$-inch main which runs along the front wall and descends to the level of the combustion laboratory floor, where it enters a salt-glazed stoneware tower packed with coke, and provided with a water shower. Passing up this, which is $2 \mathrm{ft}$. $6 \mathrm{in}$. diameter and $\mathrm{I} 3 \mathrm{ft}$, 6in. high, the washed fume is carried by another 12 -inch pipe to the ground level again, and enters the ashpit of a furnace $4 \mathrm{ft}$. $\times$ Ift., which has fire-brick doors closing air-tight against planed cast-iron rims. Separate 8-inch pipes communicating with the 12 .inch main go to each fume cupboard, and when the furnace is alight a most powerful draught, amounting to about 12,000 cubic feet of air per hour, is drawn from the benches and fume cupboards.

'The stone muffle benches are each provided with a

NO. I 259 , VOL. 49] 
small flue in the wall, and will accommodate eight fullsized gas muffles. All the gas, water, heating, and fume pipes, together with the drains, which have specially arranged intercepting tanks to prevent the loss of mercury or the carrying of solid matter into the sewers, are carried beneath the benches in an ample stone-paved recess below the floor level. There is an easy means of access to all these pipes by sliding out the bottoms of the apparatus stores, which are arranged below each bench, and protected by an iron foot-rail.

Air from outside is also admitted from the same space, and is thus slightly warmed before entering the laboratory. The glass lights in the roof can, if desired, be opened. Artificial light is provided by six powerful self-ventilating Wenham gas-lamps, but it is hoped in time to provide incandescent electric lights to each bench.

Just outside the laboratory is a balance room fitted with six Oertling balances; this room is small, but the exigencies of the site did not permit of a larger area. Opposite the balance room a spiral staircase enables the examiner in charge to at once descend to the combustion laboratory. This room, $23 \times \mathrm{I}_{3}$, is fitted with seven stone-topped combustion benches, each $4 \mathrm{ft}$. 6in. $x$ Ift. 3 in., provided with a $\frac{3}{4}$ in. fullway gas cock. Behind this is a vault lighted by prism light in the laboratory floor, in which is placed a powerful high-pressure water heating apparatus. Outside in the area is a washing-up room, provided with requisite shelves, sink, \&c., and supplied with gas, so that the rougher operations of a laboratory, the handling of carboys, storage of acids and bulky chemicals, \&c., can there take place.

From the house the laboratory is entered by a corridor starting from the cloak-room. The latter is large and amply provided with all necessaries, and with it communicates a commodious and well-fitted lavatory, having hot and cold water and all necessary fittings.

Behind the office, a handsome oak-floored room in the house itself will serve as a suitable laboratory for gas analyses.

Besides the accommodation here described, the house contains fifteen large rooms and a fine entrance hall. On the ground floor the front room serves as the office. The first floor supplies two large council and committee rooms, while the basement furnishes the housekeeper with ample accommodation. It will thus be seen that there is plenty of room for expansion.

The proverbial delays of the law prevented the House Committee from getting to work until August had begun. Its members are to be congratulated on the work they have done, and the time, four months, in which it has been accomplished.

The opening of the laboratories took place on Friday, December 8, at one o'clock, when the President received a number of gentlemen, who subsequently inspected the new buildings. The company included Sir F. Abel, F.R.S., Dr. Bell, F.R.S., Dr. H. E. Armstrong, F.R.S., Dr. Russell, F.R.S., Prof. Ramsay, F.R.S., Prof. Hartley, F.R.S., Prof. Clowes, Mr. C. E. Groves, F.R.S., Prof. Meldola, F.R.S., Mr. R. J. Friswell, Mr. O. Hehner, Dr. T. A. Lawson, Mr. D. Howard, Mr. Ernest Hart, and many other gentlemen and representatives of the press. Letters and telegrams regretting absence were received from Sir W. Foster, M.P., Sir H. Roscoe, M.P., Mr. Fowler, M.P., Mr. Norman Lockyer, F.R.S., Prof. J. M. Thomson, the Duke of Bedford, \&c.

At half past one the President delivered a short address dealing with the history and objects of the Institute, which now consists of $73 \mathrm{I}$ fellows and IO4 associates, and has 200 registered students on its books. On the conclusion of this brief ceremony the laboratories being declared open, the President invited the assembled NO. I 259 , VOL. 44] company to luncheon, which was laid in the council rooms. Sir F. Abel proposed the President's health, to which Dr. Tilden briefly replied, after which the meeting broke up.

\section{SCIENCE IN THE MAGAZINES.}

R. A. R. WALLACE contributes to the Fortnightly the second part of his article on "The Ice Age and its Work." He deals in detail with the erosion of lake basins, first describing the different kinds of lakes, and their distribution, and then the conditions that favour the production of lakes by ice-erosion. The objections of modern writers are afterwards considered seriatim, and the manner in which they are handled will give pleasure to all glacialists. The alternative theory to that of ice-erosion, for the origin of the class of lakes discussed, viz. that they were formed before the glacial epoch, by earth movements of the same nature as those concerned in mountain formation, appears to be fairly presented, and the difficulties in the way of accepting it are pointed out. Evidence is adduced to show that the contours and outlines of the lakes in question indicate erosion rather than submergence, and, finally, the Lake of Geneva is taken as a test of the two rival theories. As the subject discussed is very complex, and the argument essentially a cumulative one, Dr. Wallace gives the following summary of the main points :-

In the first place, it has been shown that the valley lakes of highly glaciated districts form a distinct class, which are highly characteristic, if not altogether peculiar, since in none of the mountain ranges of the tropics, or of non-glaciated regions over the whole world, are any similar lakes to be found.

The special conditions favourable to the erosion of lakebasins, and the mode of action of the ice-tool, are then discussed, and it is shown that these conditions have been either overlooked or ignored by the opponents of the theory of iceerosion.

The objections of modern writers are then considered, and they are shown to be founded either on mistaken ideas as to the móde of erosion by glaciers, or on not taking into account results of glacier-action which they themselves either admit or have not attempted to disprove.

The alternative theory-that earth-movements of various kinds led to the production of lake-basins in all mountain ranges, and that those in glaciated regions were preserved by bing filled with ice-is shown to be beset with numerous difficulties, physical, geological, and geographical, which its supporters have not attempted to overcome. It is also pointed out that this theory in no way explains the occurrence of the largest and deepest lake; in the largest river valleys, or in those valleys where there was the greatest concentration of glaciers, a peculiarity of their distribution which points directly and unmistakably to ice-erosion.

A crucial test of the two theories is then suggested, and it is shown that both the sub-aqueous contours of the lake-basins, and the superficial outlines of the lakes, are exactly such as would be produced by ice-erosion, while they could not possibly have been caused by submergence due to any form of earthmovements. It is submitied that we have here a positive criterion, now adduced for the first time, which is absolutely fatal to any theory of submersion.

Lastly, the special case of the Lake of Geneva is discussed, and it is shown that the explanation put forth by the antiglacialists is wholly unsupported by facts, and is opposed to the known laws of glacier motion.

The Contemporary is included among the magazines that we have received, and to it Mr. Herbert Spencer contributes a rejoinder to Prof. Weismann. "As a species of literature," he remarks, "controversy is characterised by a terrible fertility. Each proposition becomes the parent of half-a-dozen, so that a few replies and rejoinders produce an ummanageable population of 